\title{
Computer Simulation of High-Speed Anodic Dissolution Processes of Geometrically-Complex Surfaces of GTE Details
}

\author{
Maxim V. Nekhoroshev", Nikolay D. Pronichev and Gennadiy V. Smirnov
}

Samara State Aerospace University, 443086, Samara, Russia

\begin{abstract}
Electrochemical machining (ECM) is widely used in modern aircraft engine technology. This method was developed on a step-by-step basis in accordance with development of gas turbine equipment. Introduction of new difficult to machine materials into engines designs and improvement of accuracy of detail geometric parameters required new technological solutions. ECM method has a number of advantages: zero tool wear, the process does not depend on physical-mechanical properties of work piece material, no heat and force action on a work piece; these facts provide high quality of the surface layer and increase engine life. However, electrochemical machining has also disadvantages which essentially limit its applicability. This is primarily a low localization of ECM process. In order to eliminate this disadvantage new ECM schemes were developed, inter-electrode gap was reduced, switched mode power supply units, vibration of electrochemical machining electrode, etc. were used. Electrochemical machines design became more complicated and ECM operations design techniques required new solutions, therefore the scientific inquiry in this area continued intensively. Rapid development of computer technology contributed to the creation of digital models that adequately describe processes in the inter-electrode spacing at ECM. It is necessary to create electronic databases for various electrochemical metal-electrolyte systems, to develop techniques to simulate electric fields in the inter-electrode spacing, and to profile tool electrode automatically. The authors carried out active researches in this area at all stages of ECM development; they have a large number of publications in the field, including 4 monographs.
\end{abstract}

Keywords: Aero engine components, electrochemical machining (ECM), electrolyte, simulation.

\section{INTRODUCTION}

When designing dimensional TCM of GTE airfoils the most time-consuming tasks are to determine optimal operating modes and to profile electrochemical machining electrode. One of the ways to reduce the cycle of process preparation and expenditures connected with the designing is to create a model of ECM process and to use it in order to solve these two major problems. Description of the ECM process in general is a complex system of adjoint problems: hydraulic, thermal, convection, diffusion, chemical reactions, electric field. One of the fundamental works devoted to this matter is the work [1]. The outcome of these tasks is the obtaining of curent denity distribution in the inter-electrode gap and the corresponding quantities of material removed [2]. Selection of ECM model is always associated with certain assumptions that affect the adequacy of the model and consequently the accuracy of the solutions. For example, in the work [3], the authors propose a model obtained by solving all the above adjoint problems, but the authors set some of the parameters used (heat transfer coefficient, electrical conductivity) as constant or indicate their variation range depending on other parameters, based on the results of preliminary experimental studies of samples under appropriate processing modes. At that the authors simulate both the process of blade airfoil dissolution at a given airfoil of the tool electrodeand airfoil, tool electrodecopying using reference blades with reverse polarity.

In other studies [4-7] similar problems of modeling of ECM process of complex channel-bladed integrated disk impeller passage were solved in order to obtain a description of the complex movement trajectory of the electrode with a view to its subsequent use in CAD/CAM/CAE systems when processing on $\mathrm{CNC}$ machines [8]. At the same time a part of the parameters was set as constant and obtained by preliminary experiments. In the course of solving the electrolyte flow rate and the shape of the tool cathode were optimized

\section{METHOD}

This work is a continuation of the series of works on the subject of ECM information modeling [9-11]. When developing computer models of formation at ECM it is necessary to use databases containing information on electrolytes compositions, machining conditions, polarization curves for cathode and anode materials.

On the basis of the authors' researches in potentials and current distribution in the electrode spacing a methodology of forming simulation at ECM, based on the iterative calculation of current density at any point on anode surface using the ANSYS program. Typically, the ANSYS program is used for system strength analysis in design in aircraft engine engineering [12], but it also allows to simulate electric fields and other associated processes. The following data are assumes as the souse ones: an initial anode and 
cathode voltage; a composition and concentration of the electrolyte and its electrical conductivity; polarization curves for these conditions, obtained by preliminary experimental studies of flat samples under similar machining conditions; current output for process material. The resulting intensity and direction of current, and their changes in analyzed area determine the machined surface profile formation. An alternative way to solve this problem is an analytical approach discussed in the article using the Fourier series expansion of analytic functions describing a dissolution boundary of a work piece [13]. The resulting conformal mappings are then used to express the shape of the tool electrode. The tool profile is expressed as a series, each member of which is an analytic function of the corresponding work piece harmonic. The offered numerical modeling method is more convenient for practical use at the place of production, as it requires no special mathematical training of the user.

The developed models were taken as a basis of created separate exterior modules for modeling of ECM of standard basic elements of geometry. A generalized block diagram of such modules shown in Fig. (1).

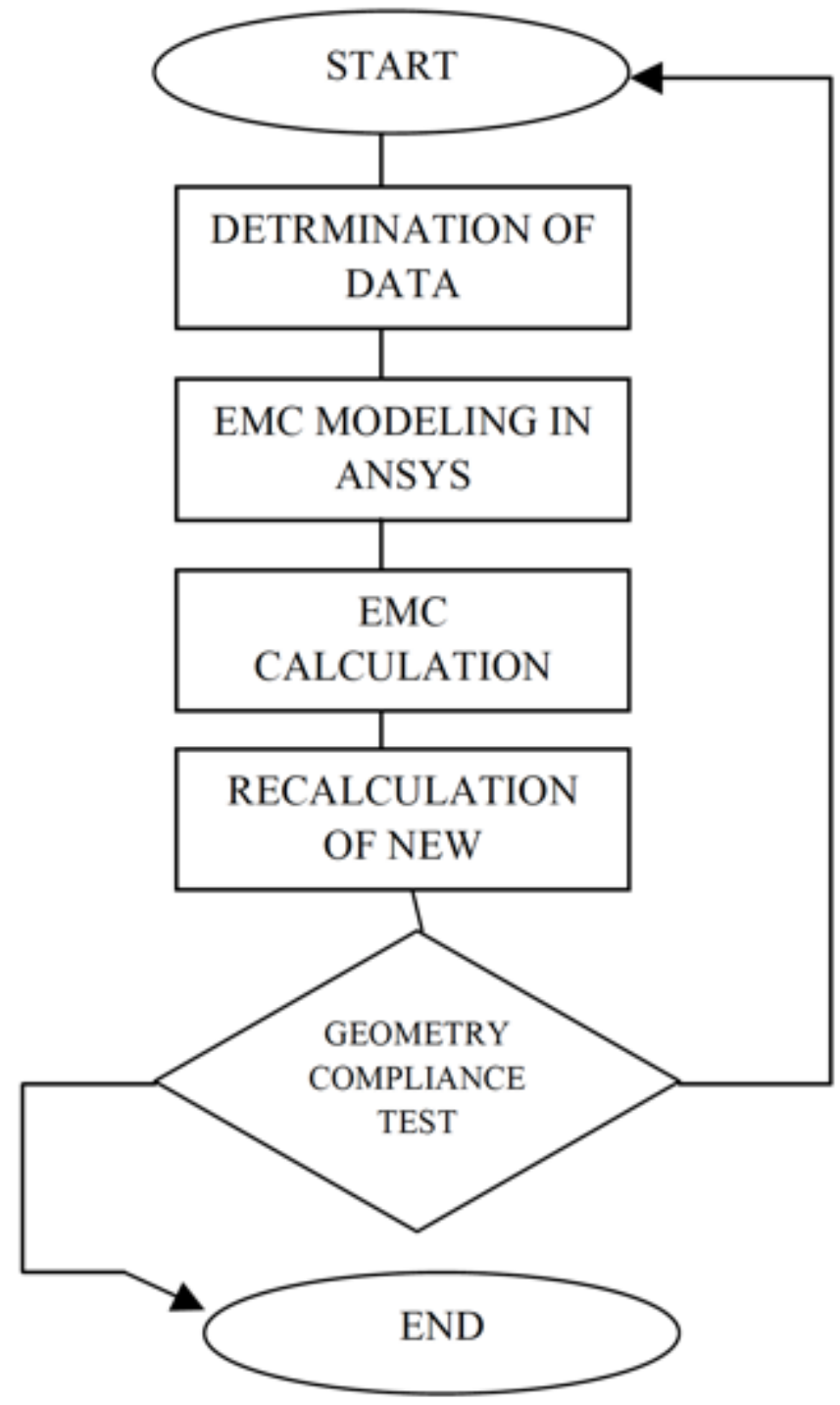

Fig. (1). Block diagram of the electronic model operation.
These modules allow to enter source data (geometric parameters, machining modes, polarization recording, etc.) interactively and to analyze obtained results of dissolution in real time, moreover they help to obtain optimal machining modes automatically Fig. (2). It should be noted that the developed modules are included into the software package "Automated workstation of electrochemical machining operations technologist" ("AWS of technologistelectrochemist"), which will help to reduce time and cost at the stage of technological preparation of geometricallycomplex parts production.

The work of the modules is to enter initial information in macros, to run a calculation with intermediate control at every iteration of conformity of profile surface set within size tolerances. The calculation is stopped if at least one of the points of the machined surface reaches the lower limit of the tolerance zone or fall outside the limits. The modules also form bases of intermediate results in the form of profiles of obtained surfaces at different stages of machining and at choice of optimal machining modes.

Potentials secondary distribution arising during electrochemical machining operations is carried out in these modules. For this purpose, experimental researches aimed to obtain polarization curves for different materials and electrolytes were carried out.

The modules also consider features of the electrolyte in which EMS is carried out (conductivity, concentration, temperature, etc.). All the data obtained were systematized and added to a database, from which the user selects the desired polarization dependence for known work piece and electrode materials, and for electrolyte composition.

\section{RESULTS}

The simulation results Fig. (3) were compared with the experimental results obtained at a pilot plant. Geometry of the machined samples surfaces was monitored at an inspection machine for its subsequent comparison with the information model Fig. (4).

The comparison showed that the difference between the results of simulation and measurements at inspection machine does not exceed $8 \%$, this fact indicates a good reproducibility and shows the adequacy of ECM computer model, which considers electrodes polarization.

Based on the standard models a method of modeling of electrochemical machining of the blade airfoil of gas-turbine engines was developed.

A task of computer modeling of two-sided machining of the blade airfoil, considering electrolyte flow hydrodynamic and its effect on the blade deformation during EMC Fig. (5) was set.

A conjugate model of electrochemical forming of the blade airfoil was created as well. Using the software package FLUENT pressure distribution in the inter-electrode gap was determined, this pressure distribution was taken into account during the calculation of blade deformations, influencing the gaps change and the nature of forming of the blade back and pressure side by analogy with the approach taken in the works (Wu et al., 2011) [14]. In contrast to the models 




Fig. (2). Main menu of the developed modules.
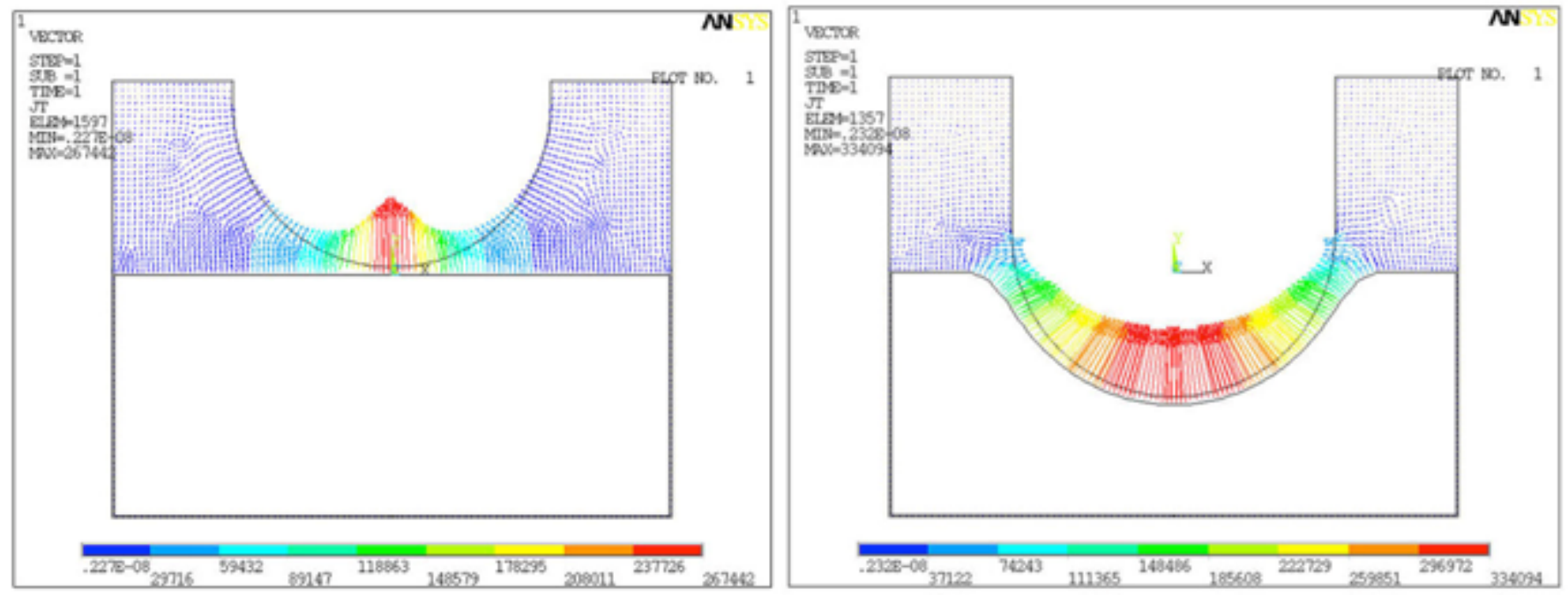

Fig. (3). Simulation results for a spherical electrode at the initial stage of machining and after 12 minutes for the material St20 on the electrolyte $\mathrm{NaCl}(20 \%)$.

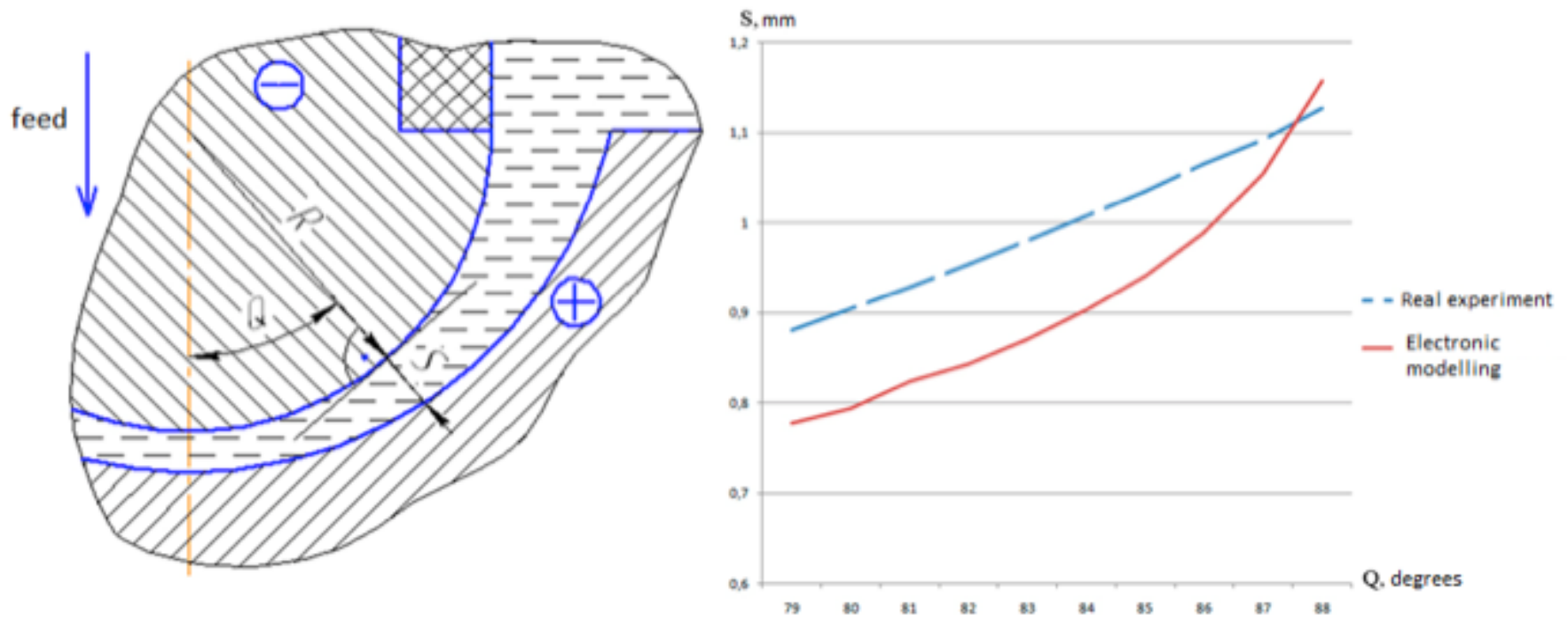

Fig. (4). Scheme of inter-electrode gap variation for EMC and the obtained results of comparison. 


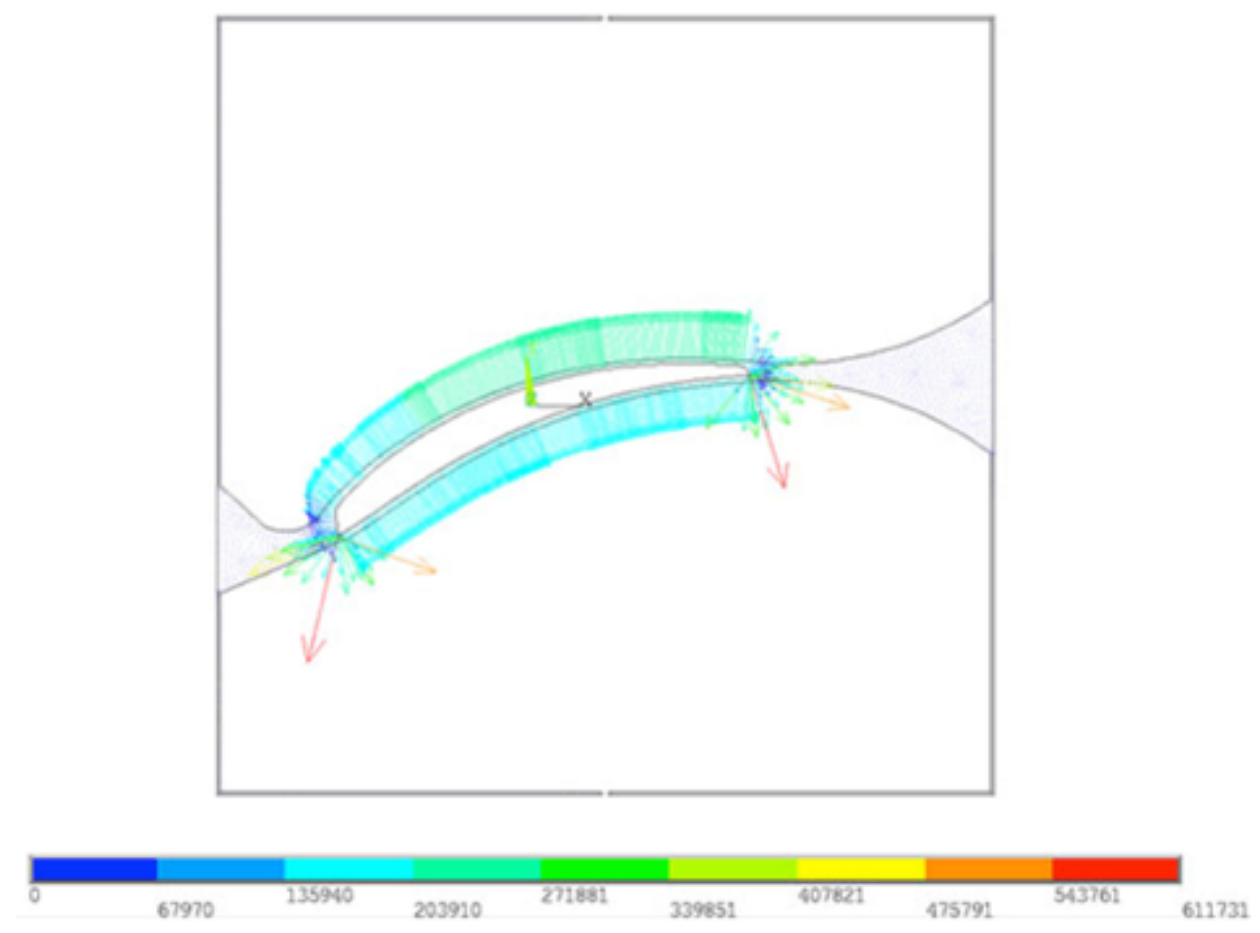

Fig. (5). Mathematical model of EMC characteristic section of the blade airfoil of gas-turbine engine compressor.

discussed, we used an approach with "the particular reference to the actual machining conditions", which facilitates this problem solution greatly. In the proposed models a common approach to modeling not connected with specific machining conditions was used. Hence, there are quite serious requirements to determination of machining parameters in the description of the dissolution process, requiring postulation of some difficult to determine parameters either by preliminary experiments or by references to similar experiments of other authors. We offer a method of EMC simulation that simplifies the calculation process significantly and is based on the results of experimental studies of the EMS process in a plane-parallel slot under similar conditions for different inter-electrode gaps. At the same time the researches results are connected to specific power supply conditions machine-power supply unit. As a result of the study, the obtained current-interelectrode gap and voltage-inter-electrode gap relationships implicitly include all complex processes of hydraulics, electrode polarization, diffusion and thermal processes, and ultimately determine natural distribution of electric current density in the inter-electrode gap.

\section{DISCUSSION}

The results obtained correspond to the level reached in the works $(1,2$, №, 4) according to a degree of approaching to the experimental data. The model can adequately describe the processes of dissolution on the smooth surfaces of the back and the pressure side of the blade. In case of field inverting and electrode materials change the inverse problem can be solved-profiling of electrodes for blade machining. Simple inversion of the field without any corresponding changes of electrodes materials, as stated in the work [3], may lead to significant errors of the airfoil due to the change of nature of processes in electrodes. The results represent dissolution processes adequately, despite the fact that a two- dimensional simulation was used in contrast to the approach adopted in the work [15], where a three-dimensional simulation was used. It is worth noting that the twodimensional simulation simplifies the solution process significantly while maintaining the required accuracy. Using this approach, the calculation within the clock cycle allowed to take a number of engineering assumptions:

- $\quad$ in the intervals of a small time step at each reference point the characteristics of the electrochemical process (electrolyte electrical conductivity, current output, anode and cathode electrode potentials value) were assumed as constant;

- the boundary condition on the anode surface is given by the potential value, which depends on the current density. This model considers the electrodes polarization.

\section{CONCLUSION}

This article describes a technique that allows to make calculations of electric fields in an electrochemical slot at EMC conditions using the ANSYS program. The calculations made in the ANSYS program confirmed the results obtained using conductive paper and showed that the computer model reflects the potentials (currents) distribution law in an electrochemical slot.

On the basis of the researches a database was created. This database includes the characteristics of materials and electrolytes, the curves of current efficiency and the polarization curves. These graphs are given in tabular form for the subsequent iterative calculations in ANSYS.

Also, the authors have implemented a method of calculation by macros using the ANSYS program. This technique helped to simplify the calculation process and its automation in the program ANSYS. Macros ensuring 
simulation conditions fulfillment were created. The resulting method allows to simulate both the blade-work piece dissolution process and inverse copying of tool electrode from the reference work piece when inverting the electric field, by analogy with the results of the work [3].

However, the developed modules have some disadvantages: the simulation can be carried out only for direct current (it is planned to carry out a series of physical experiments that will allow to implement a model of formation for pulse current in future), a number of assumptions influencing the formation at EMC were taken.

\section{ABOUT THE AUTHORS}

The first author is Nehoroshev Maxim Vladimirovich, teaching assistant of the Department of aircraft engine manufacturing of Samara State Aerospace University. Research interests: Computer simulation of electrochemical machining. CAD and CAE computer modeling of technological processes.

The second author is Pronichev Nikolai Dmitrievich, Doctor of Engineering, professor of the Department of aircraft engine manufacturing of Samara State Aerospace University. Research interests: the hydrogen absorption of titanium alloys surface at EMC.

The third author is Smirnov Gennady Vladimirovich, Doctor of Engineering, professor of the Department of aircraft engine manufacturing of Samara State Aerospace University. Research interests: localization of etching process at EMC.

\section{CONFLICT OF INTEREST}

The authors confirm that this article content has no conflict of interest.

\section{ACKNOWLEDGEMENTS}

This work was financially supported by the Government of the Russian Federation (Ministry of Education and science) in execution of the RF Government Decree No. 218 dtd. 09.04.2010 (subject code 2013-218-04-4777).

This work was supported by the Ministry of education and science of the Russian Federation in the framework of the implementation of the Program of increasing the competitiveness of SSAU among the world's leading scientific and educational centers for 2013-2020 years.

\section{REFERENCES}

[1] N.P. Gnusin, "Physical and mathematical formulation of the problem of electric fields in electrolytes", Novosibirsk: Nauka, pp. 273, 1972.

[2] D. Zhu and K.P. Rajurkar, "Modeling and verification of interelectrode gap in electrochemical machining with passivating electrolyte", Manufacturing Science and Engineering, vol. 10, pp. 589-96, 1999.

[3] F. Klocke, M. Zeis, S. Harst, A. Klink, D. Veselovac and M Baumgärtner, "Modeling and simulation of the electrochemical machining (ECM) material removal process for the manufacture of aero engine components", Procedia CIRP, vol. 8, pp. 265-70, 2013.

[4] F. Wang, J. Xu and J. Zhao, "Process and test of electrochemical machining of large diameter integral impeller by fractional step machining method", Hangkong Xuebao/Acta Aeronautica et Astronautica Sinica, vol. 31, pp. 2450-6, 2010.

[5] R. Wu, D. Zhang, and J. Sun, "3-D flow field of cathode design for NC precision electrochemical: Machining integer impeller based on CFD", Research Journal of Applied Sciences, Engineering and Technology, vol. 3, pp. 1007-13, 2011.

[6] J. Zhao, F. Wang, J. Xu and Y. Liu, "Research on electrochemical machining process for fine finishing of integral impeller with freeform surface blade", Hangkong Xuebao/Acta Aeronautica et Astronautica Sinica, vol. 34, pp. 2841-48, 2013.

[7] D. Zhu, D. Zhu and Z. Xu, "Optimal design of the sheet cathode using W-shaped electrolyte flow mode in ECM", International Journal of Advanced Manufacturing Technology, vol. 62, pp. 14756, 2012.

[8] D.V. Evdokimov, D.G. Fedorov, and D.L. Skuratov, "Thermal stress resarch of processing and formation of residual stress when end milling of a workpiece", World Applied Sciences Journal, vol. 31, pp. 51-5, 2014.

[9] M.V. Nekhoroshev, N.D. Pronichev, and G.V. Smirnov, "Automation of designing technology of electrochemical processing GTE blades penon the basis computer simulation of morphogenesis", Proceedings of the Samara Scientific Center, Russian Academy of Sciences, vol. 6, pp. 897-900, 2013.

[10] N.D. Pronichev, M.V. Nekhoroshev, and V.G. Smelov, "Development of the technology of electrochemical firmware holes using computer simulations", Russian Academy of Sciences, pp. 221-4, 2009.

[11] V.A. Shmanev, V.G. Filimoshin, A. Karimov and N.D. Pronichev, "Electrochemical machining technology in aircraft engine", Mashinostroenie, 1986.

[12] D.P. Davydov, "Construction of finite element rod blades as part swing-symmetric system impeller", Vestnik SSAU, vol. 2, pp. 1726,2011 .

[13] G.M. Alder, D. Clifton, and F. Mill, "A direct analytical solution to the tool design problem in electrochemical machining under steady state conditions", Proceedings of the Institution of Mechanical Engineers, Part B: Journal of Engineering Manufacture, vol. 214, pp. 745-50, 2000.

[14] S. Skoczypiec, "Research on ultrasonically assisted electrochemical machining process", International Journal of Advanced Manufacturing Technology, vol. 52, pp. 565-74, 2011.

[15] M. Purcar, A. Dorochenko, L. Bortels, J. Deconinck and B. Van den Bossche, "Advanced CAD integrated approach for 3D electrochemical machining simulations", Journal of Materials Processing Technology, vol. 203, pp. 58-71, 2008. 